\title{
Correction to: Elevation of miR-146a Inhibits BTG2/BAX Expression to Ameliorate Postoperative Cognitive Dysfunction Following Probiotics (De Simone Formulation) Treatment
}

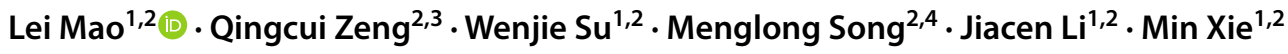 \\ Published online: 23 February 2022 \\ ○) Springer Science+Business Media, LLC, part of Springer Nature 2022
}

Correction to: Molecular Neurobiology (2021) 58:3457-3470

https://doi.org/10.1007/s12035-021-02330-z

The authors have corrected the formula "VSL\#3" to "De Simone Formulation (DSF)" in all occurrences in the manuscript.

Publisher's Note Springer Nature remains neutral with regard to jurisdictional claims in published maps and institutional affiliations.

The original article can be found online at https://doi.org/10.1007/ s12035-021-02330-z.

Jiacen Li

lijiacen1014@163.com

$\triangle$ Min Xie

xiemin039@163.com

1 Department of Anesthesiology, Sichuan Provincial People's Hospital, University of Electronic Science and Technology of China, No. 32, West Second Section, First Ring Road, Qingyang District, Chengdu 610072, Sichuan Province, People's Republic of China

2 Chinese Academy of Sciences Sichuan Translational Medicine Research Hospital, No. 32, West Second Section, First Ring Road, Qingyang District, Chengdu 610072, Sichuan Province, People's Republic of China

3 Geriatric Intensive Care Unit, Sichuan Provincial People's Hospital, University of Electronic Science and Technology of China, Chengdu 610072, People's Republic of China

4 Emergency Intensive Care Unit, Sichuan Provincial People's Hospital, University of Electronic Science and Technology of China, Chengdu 610072, People's Republic of China 